ORIGINAL ARTICLE

\title{
The effect of altitude and progressive exercise activity on the profile of testosterone changes and Some of immunity markers in active student basketball team
}

\author{
Maria Rahmani Ghobadi ${ }^{1 \mathrm{ABCDE}}$, Sepehr Taghavi Dehaghani ${ }^{2 \mathrm{ABCDE}}$, Mohammadreza Nazari ${ }^{3 \mathrm{ABCDE}}$ \\ ${ }^{1}$ Damavand Branch, Islamic Azad University, Damavand, Iran \\ ${ }^{2}$ South Tehran Branch, Islamic Azad University, Tehran, Iran \\ ${ }^{3}$ Roudehen Branch, Islamic Azad University, Roudehen, Iran
}

Authors Contribution: A - Study design; B - Data collection; C - Statistical analysis; D - Manuscript Preparation; E - Funds Collection.

\begin{abstract}
Purpose: $\quad$ Training activities and altitude cause some of changes in the physiological adaptations and also athletic functionality. The purpose of this study was the effect of altitude and progressive exercise activity on the profile of testosterone changes and Some of immunity markers in active student basketball team.

Material: $\quad$ As to subjects this survey, 36 active male students with an average age of (19.5 \pm 0.83$)$ were selected from 36 athletes with a maximum rate of oxygen uptake of about $\left(\mathrm{VO}_{2 \max }=58.66 \pm 2.9\right)$. The subjects, who were tested in the sea level $f$ and post IAE ( 8 of periodical ascending to the height of 2800 meters for 3 days), were then asked on cycle ergometer (starting with 100 watts, increasing 25 watts every 3 minutes, with the work-torest ratio of 3 to 1 ) to exhaustion. The initial blood sampling of the subjects was done 72 hours before the main test to determine the similar conditions of the subjects, and to measure the initial level of Testosterone hormone, lymphocytes and neutrophiles, in the sea level. Also, the blood sampling of both after and before the progressive exercise activity and the IAE stage were done. The serumal concentration of testosterone was measured via Elisa method and the amounts of lymphocytes and neutrophiles were determined using CellCounter set. For statistical analysis, using the tests of Kolmogorov and Smirnov, repeated measurements were done in the level of $(p \leq 0.05)$. The complete process of analyzing the result was done through the software SPSS22.
\end{abstract}

Results: $\quad$ The outcomes of the present survey show the amount of lymphocytes and neutrophiles after a session of progressive exercise activity have had a meaningful increase $(p<0.05)$. But, the increase rate of testosterone was not meaningful difference ( $p>0.05$ ). Testosterone, lymphocytes and neutrophiles showed a meaningful increase after progressive exercise activity in IAE conditions $(p<0.05)$. Also, the amounts of Testosterone, lymphocytes and neutrophiles, before IAE has not shown a meaningful rise, when compared to sea level conditions ( $p>0.05)$.

Conclusions: It seems that, even though these changes were not meaningful, they were effective in reducing both the functionality of the subjects and the exhaustion duration.

Keywords: intermittent altitude, progressive exercise activity, testosterone, immunity markers.

\section{Introduction}

Many people, such as athletes and tourists, are exposed to altitude for various purposes. Climbers, skiers and sports teams that have to compete at different heights are also included [1]. Long-lasting activities related to oxygen transfer and aerobic energy apparatus are more likely to be influenced by low-pressure ambient conditions [2]. Height training is often used by endurance athletes who seek to improve their performance at sea level [3]. Several studies have shown group improvement in post-sea level performance and training at altitude [4].

Mounting time and elevation are the most important indicators for improving sea level performance. So far, different strategies or programs have been used to examine the effect of height on the body; the first is "Living at High Altitude and Practicing Low Altitude" [5]. These two methods of height training had a positive effect on physical function $[6,7]$. The third is "High (c) Maria Rahmani Ghobadi, Sepehr Taghavi Dehaghani,

Mohammadreza Nazari, 2020

doi:10.15561/20755279.2020.0106
Altitude Life and Practice." Although there is little research on this method, the question arises whether low altitude (1000-1500 m) or medium $(1800-2500 \mathrm{~m})$ causes changes in indices. Physiological, hematological and functional in athletes at sea level $[8,9,10]$. Moderate elevation may result in high hematologic markers [8]. Most studies on functional [8, 10] and hematologic responses to moderate or high altitude burden On runners and cyclists [10]. Athletes, military, climbers, and those who do high-intensity, high-intensity physical activity achieve improved muscle function after 2 to 3 weeks of continuous elevation [11]. While continuing to stay at altitude may result in losses such as isolation due to lack or lack of accommodation and safety support [12], increased stress or oxidative stress [13], sleep disturbance [14], and general discomfort or boredom. In comparison, IAE (Intermittent Altitude Exposure) daily eliminates or minimizes these losses, thus suggesting alternate exposure to elevated or hypoxic conditions may be more acceptable [15]. Athletes, military, and climbers may also 
not have enough time to gain altitude accidents during a 2 to 3-week altitude stay. Therefore, alternating daily with hypoxic (Oxygen deficiency) and hypobaric (reducing barley pressure) conditions will have significant benefits [15].

Recent studies show that daily short-term altitude (IAE) exposure for three weeks (four hours a day, five days a week) is as effective as three weeks of altitude exercise in reducing the severity of acute mountain disease, poor performance (physical activity) and physiological adaptation [16]. However, although the benefits of positive reasoning and positive physiology (IAE) have been clearly identified, But the potential negative effects of (IAE) on health, especially in thirty immune systems, remain undefined [16].

Studies have shown that following intense acute endurance training, several components of the immune system stop within a few hours, occurring from 3 to 24 hours after acute and endurance training, when the host's defensive power is reduced [17]. These components include the number and function of neutrophils, lymphocytes, serum and salivary immunoglobulin concentrations, and natural killer cell adhesion [18].

Pederson \& Steensberg suggested that intense physical exercise could be used as a transient and temporary stopping substance [19]. It has been suggested in this study that although lymphocyte and neutrophil concentrations increase during and after exercise, lymphocyte concentrations decrease during intense and prolonged physical activity and exercise (a 2.5-2 h marathon) [19].

In another study, the effect of 15 to 18 minutes of pedometer pedaling on a wheelchair after 45 stress and stress was examined in 45 male subjects, resulting in an increased number of circulating leukocytes, lymphocytes, and their subpopulations [20]. However, hypoxia can not only have beneficial effects on the body. In particular, hypoxia induces marked changes in the immune system, which increase the concentration of lymphocytes and neutrophils and alter function [19]. The effect of hypoxia on leukocytes is similar to the effect of exercise. Therefore, exercise and hypoxia cause changes in leukocytes and their subunits and provide moderate ability [19].

The leukocyte response to elevation is characterized by a rapid increase in lymphocytes (in less than $30 \mathrm{~min}$ ) as well as an increase in neutrophils and lymphopenia; it is characterized by 2 to $4 \mathrm{~h}$ of elevation [21, 22]. Previous findings indicate that altitude adaptation, which occurs during constant altitude accommodation, indicates a return of WBC values and leukocyte subsets to basal levels at sea level [16].

Studies show that healthy volunteers exhibit effects similar to exposure to a height of 4,500 meters, when alternately placed in low-pressure chambers (hypobaric) and hypoxia, based on the findings of the neutrophils in them rapidly increase and the cells' ability to produce superoxidants also increases [23]. Hypobaric and mild hypoxia also result in neutrophil activation [24].

Research on untrained men has shown that both resistance training and moderate-intensity aerobic exercise, after about 15 to 20 minutes, significantly increase serum free and testosterone levels relative to rest time. On the other hand, studies show that pre-race serum testosterone was elevated above sea level $(\mathrm{P}<0.02)$, but its concentration did not change after training and elevation [25].

In a study titled "Influence of Moderate Altitude Exposure on Serum Cortisol, Aldosterone, Renin, Testosterone, and Gonadotropin Concentration", the researchers stated that within 48 hours of entering the 2000-meter mean elevation, a significant increase in testosterone levels was observed [26].

Also in another study, the salivary testosterone concentrations of native men were measured at a height of $3600 \mathrm{~m}$. The results indicate that salivary testosterone concentration in native men is significantly higher than non-native men [27].

Given the inconsistency of research reports regarding the effect of height and exercise training on safety indices (neutrophils and lymphocytes), some have been observed to increase, some to decrease, and others to no difference. Also, in some studies, there was no significant change in the relationship between the effects of exercise and exercise on testosterone. And on the other hand, given that very little research has been conducted to evaluate the impact of an exhaustive incremental training session on indicators.

At sea level, immunity (lymphocytes and neutrophils) and testosterone hormone examine IAE elevation conditions, so the present study could address some of the uncertainties about the effect of combining a fatiguing incremental training session plus IAE elevation on indices. Immune (lymphocytes and neutrophils) and testosterone hormones in active student basketball team.

The present study investigates the effect of periodic hypoxia and the increasing activity of testosterone profile and some safety indices of active student basketball team.

\section{Material and Methods}

\section{Participants}

Subjects performed one session of incremental activity on a wheelchair at sea level at an altitude of 2800 meters and were sampled in five stages. The research method is quasi-experimental.

The statistical population of this study consisted of 36 male students of Damavand Islamic Azad University basketball team in adolescents, adolescents and adolescents. Has at least three years of experience in basketball, practicing three sessions a week. Statistical examples are knowledge male students aged 18 to 22 years were selected according to the following steps.

\section{Research Design}

1. At first, the subject of the study was verbally informed about the players being available.

2. Twenty-five players announced their readiness by completing the questionnaire and the consent form.

3 . They were tested one mile (1600 meters) according to a scheduled schedule and at a specified date to 
determine the maximum oxygen consumption. The one mile run test equation (Rockport) was used to calculate $\mathrm{VO}_{2 \max }$. (Test time in minutes) - 1.438 (body weight in $\mathrm{kg}$ ) $0.1636-0.1636\left(\mathrm{VO}_{2 \max }(\mathrm{ml} / \mathrm{kg} / \mathrm{min})(\mathrm{sex})+8.344\right.$ (final heart rate test in beats per minute) 1928 is considered to be the number one for male subjects, and zero for female subjects [28].

4. Of the people who announced readiness after the one-mile test, 6 individuals with the highest oxygen consumption were selected.

Exercise protocol

To run the exercise program, the subjects first strapped the pacemaker to the chest and warmed up for five minutes and specialized warm-up on the speedometer for one minute, then began increasing activity on the pacemaker at 100 watts (With 25 watts per three minutes, work-torest ratio of 3 to 1), where subjects staggered to the limit of fatigue. In this study, the term fatigue refers to a stage in which subjects declare their inability to pedal despite being encouraged to continue working. In the final phase of the test, it took the average person 15 seconds to cool down. They did it without resistance and then blood was drawn.

\section{Steps to run the test}

In this study, $10 \mathrm{cc}$ blood samples were taken each time by a laboratory scientist with complete observation of sterile samples. And it was quickly sent to the medical diagnostic lab. Initial blood samples were taken from the subjects to determine baseline levels of cortisol and IgG to ensure normal distribution, 72 hours before the main test. Nutrition and activity of subjects 48 hours prior to exercise program were controlled. Exercise program involves increasing activity at sea level and after IAE (eight hours daily climbing 2800 meters for three days) on a wheelchair (start at 100 watts, increase 25 watts every three minutes, ratio) Work to rest 3 to 1) to the point of exhaustion. Blood samples were taken before and after increased activity. Serum testosterone concentrations were measured by ELISA and lymphocyte and neutrophil counts were measured by T-Counter.
Statistical Analysis

Kolmogorov and Smirnov tests were used for statistical analysis. Repeated measures $(\mathrm{P} \leq 0.05)$ were used for statistical analysis. All analyzes were performed using SPSS22 software analysis.

\section{Results}

Table 2 shows that there was no significant difference between testosterone and posttest seaweed levels $(\mathrm{p}=0.379, \mathrm{p}=0.811$, respectively). There was a significant difference between post-test height $(p=0.043)$. These differences in post-test sea level compared to pre-test and post-test height $(\mathrm{p}=0.655, \mathrm{p}=0.157$, respectively). Does not show any. But there was a significant difference between pre-test and post-test in height $(\mathrm{p}=0.004)$.

Therefore, increasing activity and elevation on changes in testosterone concentration at different stages is significant. Figure 1 shows the average changes of testosterone in different stages of puddle.

Statistical analysis in Table 3 shows that there is a significant difference in the amount of lymphocyte changes in pre-test and post-test at sea level $(\mathrm{p}=0.0001$, $\mathrm{p}=0.003$, respectively). There was no significant difference with height pre-test $(\mathrm{p}=0.631)$. These changes in post-test showed a significant difference $(\mathrm{P}=0.0001)$ with respect to height pre-test, whereas there was no significant difference between post-test and post-test height $(p=0.772)$. However, there was a significant difference between the pre-test and post-test at the level of level $(\mathrm{p}=0.0001)$.

Increasing activity and elevation on lymphocyte changes were significant. Figure 2 shows the average changes of lymphocytes in different stages of the study.

The results of Table 4 show that there is a significant difference in the amount of neutrophils change between pre-test and post-test sea level $(\mathrm{p}=0.0001, \mathrm{p}=0.07$, respectively), But these differences did not show a significant difference between sea pre-test and pre-test height $(p=0.225)$. The results of the table do not show a significant difference between post-test sea level and

Table 1. Mean and standard deviation of individual characteristics of subjects

\begin{tabular}{llllll}
\hline Variables & Age (Year) & $\begin{array}{l}\text { Weight } \\
(\mathrm{Kg})\end{array}$ & $\begin{array}{l}\text { Height } \\
\text { (centimeter) }\end{array}$ & $\begin{array}{l}\text { BMI } \\
(\mathrm{Kg} / \mathrm{sqm})\end{array}$ & $\begin{array}{l}\mathrm{VO}_{2 \max } \\
(\mathrm{ml} / \mathbf{k g} / \mathrm{min})\end{array}$ \\
\hline Mean $\pm S D$ & $16.5 \pm 0.83$ & $68.66 \pm 4.08$ & $183.3 \pm 7.36$ & $20.46 \pm 1.36$ & $58.66 \pm 2.9$ \\
\hline
\end{tabular}

Table 2. Test repeated tests of testosterone at various stages

\begin{tabular}{lllll}
\hline \multicolumn{1}{l}{ Statistics } & & $\begin{array}{l}\text { Average } \\
\text { difference }\end{array}$ & SD & Sig. \\
\hline \multirow{3}{*}{ Sea pre-test } & After sea test & -0.21 & 0.22 & 0.379 \\
& Pre-test height & -0.06 & 0.22 & 0.811 \\
After sea test & Post height test & $-0.89\left(^{*}\right)$ & 0.32 & 0.043 \\
Pre-test height & Pre-test height & 0.15 & 0.34 & 0.665 \\
\hline
\end{tabular}




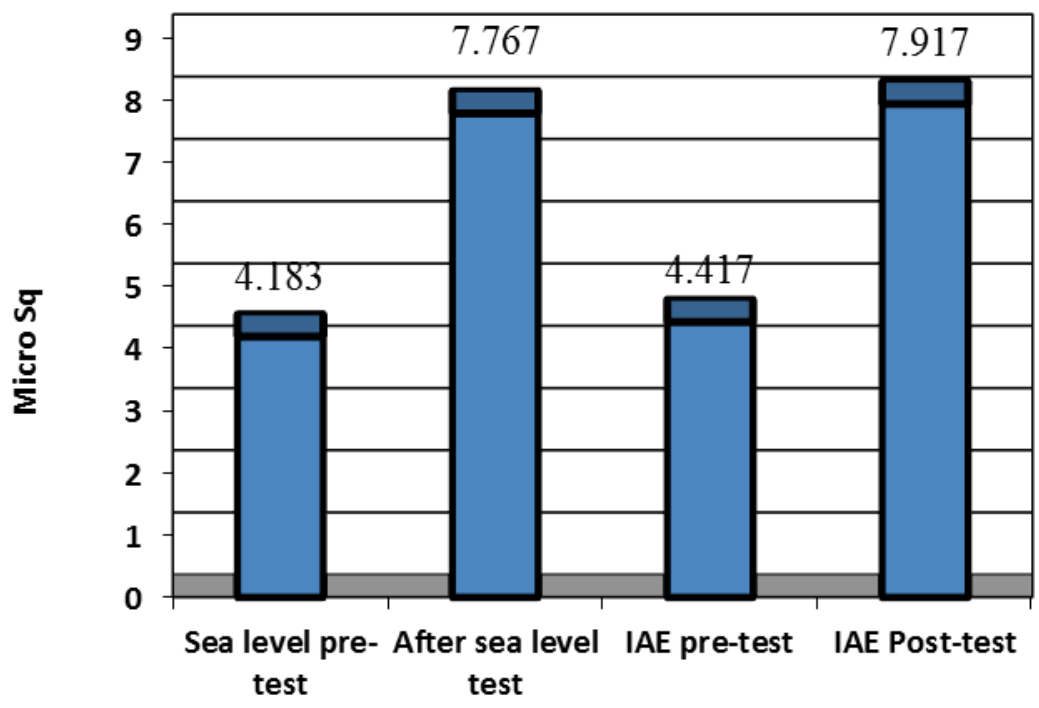

Figure 1. Average changes of testosterone in different stages of puddle

Table 3. Testing for repeated measurements of lymphocytes at different stages

\begin{tabular}{lllll}
\hline \multicolumn{1}{l}{ Statistics } & & $\begin{array}{l}\text { Average } \\
\text { difference }\end{array}$ & SD & Sig. \\
\hline \multirow{3}{*}{ Sea pre-test } & After sea test & $-3.59\left({ }^{*}\right)$ & 0.43 & 0.000 \\
& Pre-test height & -0.23 & 0.46 & 0.631 \\
\multirow{3}{*}{ After sea test } & Post height test & $-3.73\left({ }^{*}\right)$ & 0.68 & 0.003 \\
\multirow{3}{*}{ Pre-test height } & Pre-test height & $3.35(*)$ & 0.34 & 0.000 \\
& Post height test & -0.15 & 0.49 & 0.772 \\
& Post height test & $-3.5\left(^{*}\right)$ & 0.43 & 0.000 \\
\hline
\end{tabular}

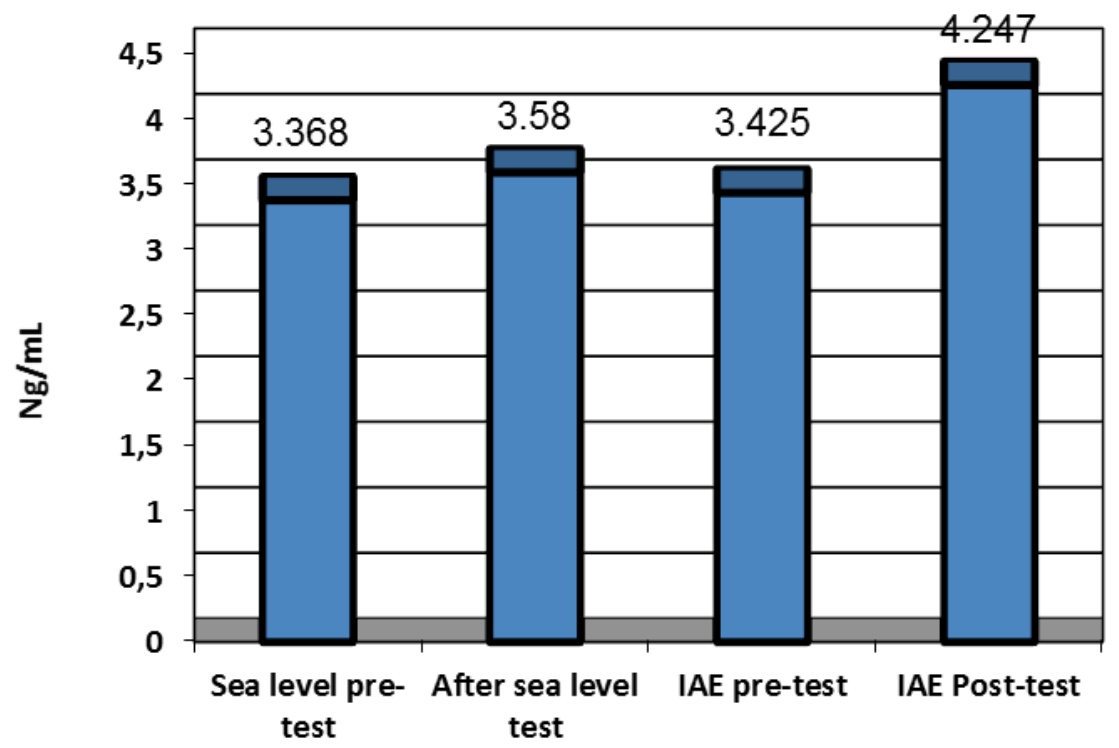

Figure 2. Mean changes in lymphocyte values 
Table 4. Test of repeated measurements of experimental neutrophils in different stages

\begin{tabular}{lllll}
\hline Statistics & & $\begin{array}{l}\text { Average } \\
\text { difference }\end{array}$ & SD & Sig. \\
\hline \multirow{3}{*}{ Sea pre-test } & After sea test & $-1.93\left(^{*}\right)$ & 0.21 & 0.000 \\
& Pre-test height & -1.02 & 0.78 & 0.252 \\
After sea test & Post height test & $-2.53\left(^{*}\right)$ & 0.82 & 0.027 \\
Pre-test height & Pre-test height & 0.92 & 0.7 & 0.249 \\
\hline
\end{tabular}

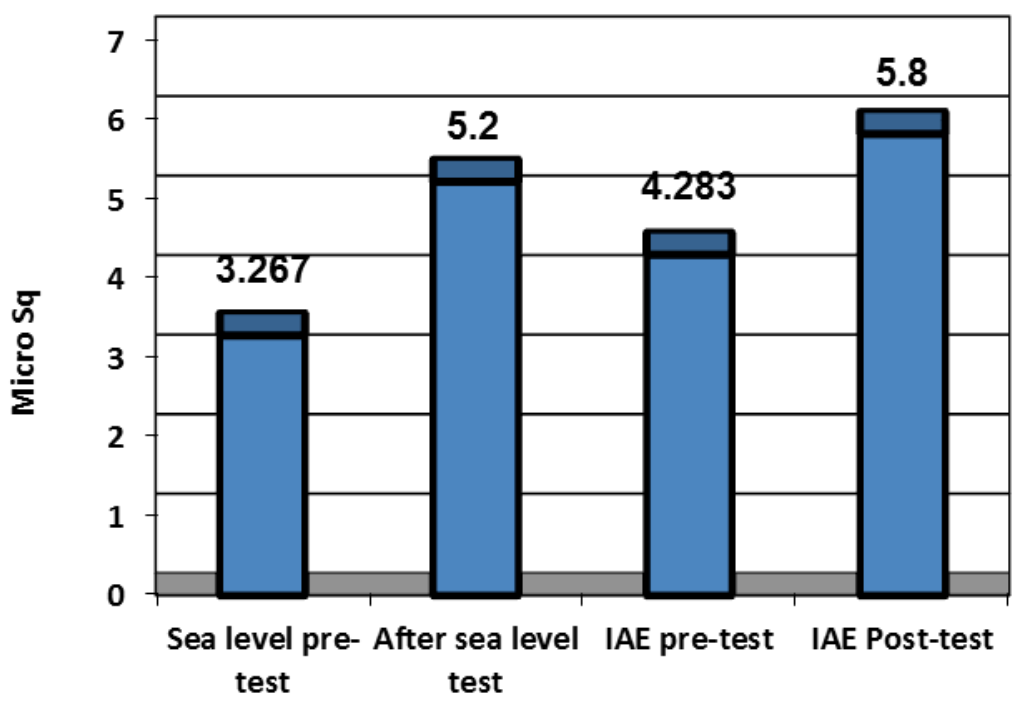

Figure 3. Average changes in neutrophil values

pre-test height and post-test height $(\mathrm{p}=0.224, \mathrm{p}=0.438$, respectively). However, there was a significant difference between pre-test height and post-test height $(\mathrm{p}=0.002)$.

According to the results of this study, the effect of increasing activity and height on neutrophil content changes. Figure 3 also shows the average of neutrophil changes at different stages of the study.

\section{Discussion}

The findings of the present study show that the serum testosterone concentration of the subjects was not significantly different from the sea level despite the increased activity and IAE (pre-test IAE) of $6.3 \%$ and $2 \%$, respectively.

But testosterone concentrations increased significantly as a result of increasing activity associated with IAE (posttest elevation) compared to pre-test sea level and IAE. Similarly, studies by Cumming et al. have not shown a significant effect of moderate-intensity aerobic and resistance training on elevated serum free testosterone levels [29]. Hakienn et al. observed a significant relationship between free testosterone and total testosterone concentrations during a 3-week training session in female students, which is consistent with the findings of the present study [30]. But studies by Hamp Lerr et al. suggest that after 48 hours' exposure to moderate altitude showed a significant increase in serum testosterone concentration [26].

However, the present research has not been able to reach this conclusion after 24 hours. [31]. Also reported a very high concentration of testosterone after exposure to hypoxic and hypobaric media, which is not consistent with the results of the present study. Also, T. Vasankari et al. in a study of skiing and racing at altitude on pituitary, adrenal and testicular function in men stated that prerace serum concentration of testosterone increased significantly above sea level. Shows that the findings of the present study do not support this finding [25]. They also stated that there was no significant change in serum concentrations of testosterone after elevation activity. Which is consistent with the findings of the present study.

On the other hand, the present findings show that there is a significant increase in lymphocytes and neutrophils due to increased activity at sea level and altitude of 2800 $\mathrm{m}$. But at the same time, these values increase after 24 hours of IAE ( 8 hours per day for three days) was not significant. Klokker et al. examined the effects of shortterm hypoxia on the cellular immune system. The results showed that blood leukocyte levels increased during hypoxia-induced strain, which was due to a significant increase in the levels of natural killer NK (lymphocytes) during hypoxia, which is consistent with the present findings [12].

Similar studies by Nielsen et al. and Pedersen \& 
Hoffman-Goetz also confirm the results of the present study by investigating the effect of intense and intense exercise activity on lymphocyte and neutrophil growth $[32,33]$. Bailey et al. in a study entitled Continuous and Intermittent Exposure to Elevation-Induced Hypoxia that Requires Glutamine Metabolism and Exercise B We reported significant changes in the level $(\mathrm{p} \leq 0.05)$ in white blood cells, lymphocytes and neutrophils, which is in line with the present research findings [34].

Yamada et al. investigated a study of the effect of activity to the extent of exhaustion on some athletes' safety indices on eight male skiers [35]. The Beidleman et al. results indicated that exercise produced a significant increase in the number of lymphocytes and neutrophils immediately after exercise relative to resting levels, which is consistent with the findings of the present study. performs a sub-maximal exercise test on a wheelchair for 30 minutes at sea level at an altitude of 4300 meters before and after the IAE (4 hours a day, 5 days a week). They found that a significant increase in the number of lymphocytes and neutrophils was observed after submaximal test and also after IAE compared to IAE pre-test and sea level, which confirms the present findings [16].

But Nieman et al. examined the immune response of elite female rowers after two hours of rowing. The results showed that there were relatively few changes in the number of leukocytes, lymphocytes and their subgroups, which is consistent with the findings of the present study [36].

Thack et al. examined 16 males by measuring the number of leukocytes and neutrophils during $4 \mathrm{~h}$ of hypoxia equivalent to $4000 \mathrm{~m}$ high. The results indicate that 4 hours of stay in hypoxic conditions causes significant changes in neutrophils and blood lymphocytes peripheral veins of the subjects, which are not in agreement with the present findings [37]. Thack et al. [37] also examined the number of leukocytes and neutrophils active during 4 $\mathrm{h}$ of hypoxia equivalent to $4000 \mathrm{~m}$ in height, the results suggest that leukocytes respond to elevation expressing rapid lymphocyte growth (in less than $30 \mathrm{~min}$ ) as well. The increase in neutrophils is after 2-4 hours of stay in hypoxia-induced elevation. While the present study did not show a significant increase in lymphocytes and neutrophils after $8 \mathrm{~h}$ in height for experimental group 1 and $24 \mathrm{~h} \operatorname{IAE}(8 \mathrm{~h}$ per day, for 3 days, $2800 \mathrm{~m}$ ) for experimental group 2 .

On the other hand, the above changes have weakened the performance of the subjects, which is $8.2 \%$ at the time of the subjects' fatigue. Therefore, it seems that repeated IAE sessions over three days can provide physiological adaptations to height and decrease Prevent performance.

\section{Conclusion}

In general, according to the findings of the present study, increased activity at sea level and associated with hypoxia induced at a height of $2800 \mathrm{~m}$ showed a significant increase in the concentration of testosterone and the levels of lymphocytes and neutrophils. However, given the lack of increased mean levels of testosterone and the amount of lymphocytes and neutrophils in hypoxia induced by the 2800-meter-high hypoxia, age, fitness, length of stay, and altitude may have been effective.

\section{Conflict of interest}

The authors declare no conflict of interest.

\section{References}

1. Radak Z, Radák Z. Free radicals in exercise and aging. Human kinetics; 2000.

2. Kenney, W. Larry, Jack H. Wilmore, David L. Costill. Physiology of sport and exercise. Human kinetics; 2015.

3. Dick F. Training at Altitude in Practice. Int $J$ Sports Med, 1992;13:S203-5. https://doi.org/10.1055/s-2007-1024640

4. Levine BD, Stray-Gundersen J. "Living high-training low": effect of moderate-altitude acclimatization with low-altitude training on performance. Journal of Applied Physiology, 1997;83:102-12. https://doi.org/10.1152/jappl.1997.83.1.102

5. Levine BD. Intermittent hypoxic training: fact and fancy. High Alt Med Biol, 2002;3: 177-93. https://doi.org/10.1089/15270290260131911

6. Stray-Gundersen J, Chapman RF, Levine BD. Living hightraininglow:altitudetrainingimprovessealevelperformancein maleandfemaleeliterunners.JApplPhysiol;2001;91:1113-20. https://doi.org/10.1152/jappl.2001.91.3.1113

7. Geiser J, Vogt M, Billeter R, Zuleger C, Belforti F, Hoppeler H. Training high-living low: changes of aerobicperformance and muscle structure with training at simulated altitude. Int $J$ Sports Med, 2001; 22: 579-85. https://doi.org/10.1055/s-2001-18521

8. Tiollier E, Schmitt L, Burnat P, Fouillot JP, Robach $\mathrm{P}$, Filaire $\mathrm{E}$, et al. Living high-training low altitude training: effects on mucosal immunity. European journal of applied physiology, 2005; 94(3): 298-304. https://doi.org/10.1007/s00421-005-1317-4

9. Mathieu-Costello O. Muscle adaptation to altitude: tissue capillarity and capacity for aerobic metabolism. High Alt Med Biol, 2001;2: 413-25. https://doi.org/10.1089/15270290152608598

10.Saunders PU, Telford RD, Pyne DB, Cunningham RB, Gore CJ, Hahn AG, et al. Improved running economy in elite runners after 20 days of simulated moderatealtitude exposure. $J$ Appl Physiol, 2004;96: 931-7. https://doi.org/10.1152/japplphysiol.00725.2003

11. Fulco CS. Effect of Menstrual Cycle Phase on Muscle Fatigue and Physical Performance During High Altitude Acclimatization. Natick, MA: US Army Res. Inst.; 1998.

12.Klokker M, Kharazmi A, Galbo H, Bygbjerg I, Pedersen BK. Influence of in vivo hypobaric hypoxia on function of lymphocytes, neutrocytes, natural killer cells, and cytokines. J Appl Physiol, 1993;74: 1100-1106. https://doi.org/10.1152/jappl.1993.74.3.1100

13.Savourey G, Garcia N, Besnard Y, Hanniquet A, Fine M, Bittel J. Physiological changes inducedby pre-adaptation to high altitude. Eur. J. Appl. Physiol, 1994;69: 221-227. https://doi.org/10.1007/bf01094792

14.Kong F. Sleep Disorder at High Altitude. Sleep Medicine in Clinical Neurology [Working Title], IntechOpen; 2019. https://doi.org/10.5772/intechopen.86727 
15.BeidlemanBA1, MuzaSR,Fulco CS, CymermanA,DitzlerDT, Stulz D, et al. Intermittent altitude exposure improve muscular performance at 4300M. J Appl Physiol, 2003; 95(5): 1824-32 https://doi.org/10.1152/japplphysiol.01160.2002

16.Beidleman BA, Muza SR, Fulco CS, Cymerman A, Staab JE, Sawka MN, et al. White blood cell and hormonal responses to $4300 \mathrm{M}$ altitude before and after intermittent altitude exposure. Clin Sci (Lond), 2006; 111(2): 163-9. https://doi.org/10.1042/CS20060012

17.Lim CL, Byrne C, Chew SAN, Mackinnon LT. Leukocyte subset responses during exercise under heat stress with carbohydrate or water intake. Aviat Space Environ Med, 2005;76:726-32.

18.MacKinnon LT. Overtraining effects on immunity and performance in athletes. Immunol Cell Biol, 2000;78:502-9. https://doi.org/10.1111/j.1440-1711.2000.t01-7-.x

19.Pedersen BK, Steensberg A. Exercise and Hypoxia: effectson leukocytes and interleukin-6 - shared mechanisms? Med Sci Sports Exerc, 2002; 34: 2004-2012. https://doi.org/10.1097/00005768-200212000-00022

20.Thake CD, Mian T, Granham AW, Mian R. Leukocyte counts and neutrophil activity during $4 \mathrm{~h}$ of hypocapnic hypoxia equivalent to 4000m. Aviat. Space Environ. Med, 2004; 75 (9): 811-7.

21.Dhabhar FS, Miller AH, McEwen BS, Spencer RL. Effect of stress on immune cell distribution. Dynamics and hormonal mechanisms. J. Immunol, 1995;154: 5511-5527.

22.Wilber RL, Holm PL, Morris DM, Dallam GM, Callan SD. Effect of FIO2 on Physiological Responses and Cycling Performance at Moderate Altitude. Medicine \& Science in Sports \& Exercise, 2003;35:1153-9. https://doi.org/10.1249/01.MSS.0000074495.34243.B5

23.Hitomi Y, Miyamura M, Mori S, Suzuki K, Kizaki T, Itoh $\mathrm{C}$, et al.. Intermittent hypobaric hypoxia increases the ability of neutrophils to generate superoxide anion in humans. Clin Exp Pharmacol Physiol, 2003;30: 659-664. https://doi.org/10.1046/j.1440-1681.2003.03891.x

24.Tamura DY, Moore EE, Partrick DA, Johnson JL, Offner PJ, Silliman CC. Acute hypoxemia in humans enhances the neutrophil inflammatory response. Shock, 2002;17(4):269-73. https://doi.org/10.1097/00024382-200204000-00005

25.Vasankari TJ1, Rusko H, Kujala UM, Huhtaniemi IT. The effect of ski Training at altitude and racing on pituitary, adrenal and testicular Function in men. European Eur J Appl Physiol Occup Physiol, 1993;66(3): 221-5. https://doi.org/10.1007/bf00235097

26. Humpeler E, Skrabal F, Bartsch G. Influence of exposure to moderate altitude on the plasma concentraton of cortisol, aldosterone, renin, testosterone, and gonadotropins. Eur
J Appl Physiol Occup Physiol. 1980;45(2-3): 167-76. https://doi.org/10.1007/bf00421324

27.Lim CL, Byrne C, Chew SA, Mackinnon LT. Leukocyte subset responses during exercise under heat srress with carbohydrate or water intake. Aviat space Environ Med, 2005;76(8): 726-732.

28.Kurdi MR, Siakohian M. Cardiopulmonary Fitness Practical Tests. Tehran: Goddess; 2004.

29.Cumming DC, Brunsting LA, Strich G, Ries AL, Rebar RW. Reproductive hormone increases to acute exercise in men. Med Sci sports Exerc, 1986; 18: 369. https://doi.org/10.1249/00005768-198608000-00001

30.Hakienn K, Pakarinen A, Alen M. Neuromuscular adaptations and serum hormones in wonen durin short-term intensive strength training. Eur $J$ Appl Physiol Occup Physiol, 1992;64(2): 106-11. https://doi.org/10.1007/bf00717946

31.Beall CM, Worthman CM, Stallings J, Strohl KP, Brittenham GM, Barragan M. Salivary testosterone concentration of Aymaramennativeto3600m.AnnHumBiol,1992;19(1):67-78. https://doi.org/10.1080/03014469200001932

32.Nielsen HB, Secher NH, Chritensen NJ, Pedersen BK. Lymphocytes and NK cell activity during repeated bouts of maximal exercise. AM J Physiol, 1996;27(1): 222-227. https://doi.org/10.1152/ajpregu.1996.271.1.R222

33.Pedersen BK, Hoffman-Goetz L. Exercis and the immune system: Regulation, Integration, and Adaptation. Physiol Rev. 2000;80(3): 1055-81. https://doi.org/10.1152/physrev.2000.80.3.1055

34.Bailey DM, Davies B, Budgett R. Recovery from infectious mononucleosis after altitude training in an elite middle distance runner. Br J Sports Med, 1997;31: 153-4. https://doi.org/10.1136/bjsm.31.2.153

35. Yamada M, Suzuki K, Kudo S, Totsuka M, Symoyama T, Nakaji S, Sugawara K. Effect of exhaustive exercise on human neutrophils in athletes. Luminescence, 2000;15(1): 15-20. h t t p s:// doi .org/ 10 . 1002 / ( S I C I ) 1522 7243(200001/02)15:1<15::AID-BIO570>3.0.CO;2-O

36.Nieman DC, Nehlsen-Cannarella SL, Fagoaga OR, Henson DA, Shannon M, Davis JM, et al. Immune response to two hours of rowing in elite female rowers. Int $J$ Sports Med, 1999; 20(7): 476-81. https://doi.org/10.1055/s-1999-8827

37. Thake CD, Mian T, Garnham AW, Mian R. Leukocyte Counts and Neutrophil Activity During $4 \mathrm{~h}$ of Hypocapnic Hypoxia Equivalent to 4000 m. Aviat Space Environ Med. 2004;75(9):811-7.

38. Thake CD, Mian T, Granham AW, Mian R. Leukocyte counts and neutrophil activity during $4 \mathrm{~h}$ of hypocapnic hypoxia equivalent to 4000 m. Aviat. Space Environ. Med. 2004; 75: 811-817. 


\section{Information about the authors:}

Maria Rahmani Ghobadi; Assistant Professor; (Corresponding Author); http://orcid.org/0000-0002-4948-6895; mrahmani. uni@gmail.com; Department of Physical Education \& Sport Sciences, Damavand Branch, Islamic Azad University; Moalem Square, Islamic Azad University, Damavand, Tehran Province, Iran.

Sepehr Taghavi Dehaghani; Sports Physiology MSc student orientation is biological; http://orcid.org/0000-0003-3926-2422; fookhoonshio@yahoo.com; South Tehran Branch, Islamic Azad University; Islamic Azad University, Tehran, Iran.

Mohammadreza Nazari; Sports Physiology MSc Student; http://orcid.org/0000-0003-1683-3106; rezanazari0529@gmail. com; Roudehen Branch, Islamic Azad University; Islamic Azad University, Roudehen, Iran.

\section{Cite this article as:}

Maria Rahmani Ghobadi, Sepehr Taghavi Dehaghani, Mohammadreza Nazari. The effect of altitude and progressive exercise activity on the profile of testosterone changes and Some of immunity markers in active student basketball team. Physical education of students, 2020;24(1):47-54. https://doi.org/10.15561/20755279.2020.0106

This is an Open Access article distributed under the terms of the Creative Commons Attribution License, which permits unrestricted use, distribution, and reproduction in any medium, provided the original work is properly cited http://creativecommons.org/licenses/by/4.0/deed.en

Received: 24.11.2019

Accepted: 23.12.2019; Published: 04.02.2020 